has proved very useful for prolonged intravenous therapy, and two drips have been maintained for 12 days without trouble. Another cephalic drip, not carried out personally, ran freely for 15 days, although the patient was very restless; about 50 litres of fluid was transfused through the drip during this time."

In three cases following prolonged intravenous therapy the vein was examined at necropsy. The sheen of the intima was lost, but there was no evidence of thrombosis. In no case has any adverse effect been noticed on prolonged use of this vein for infusion. It has also been observed that the drip can be stopped for over an hour without any interference with the subsequent flow.

Drips in the distal peripheral veins necessitate immobilization of the limb. Besides the dangers of immobilizationfor example, deep vein thrombosis-prolonged immobilization of the limb is very uncomfortable for the patient and interferes with the nursing care. The cephalic vein drip needs no more immobilization than two strips of adhesive strapping round the upper arm. In no way does it interfere with the free use of the arm, and the patient can feed himself, attend to toilet requirements, read, or pursue any other activity he wishes. It has been particularly appreciated by the nursing staff that the patients can actively co-operate in the nursing care.

\section{The External Jugular Vein}

This vein, like the cephalic, has a wide internal diameter with a minimal amount of musculature in its walls. I have used it on several occasions with success. Unfortunately it has the following drawbacks: $(a)$ it is not constant in position or size ; $(b)$ it is more difficult to expose ; $(c)$ a cannula in the neck is not as comfortable as in the upper arm; and (d) the vein passes through a tunnel of deep fascia which holds the walls apart; it is therefore liable to air embolism, as proved in the case reported by Sir Bernard Spilsbury:

\section{Summary}

The cephalic vein, in the delto-pectoral groove, has been used for intravenous therapy on 41 occasions.

The superiority of this vein over the other veins of the body has been appreciated in rapid transfusion, in "shock," and in prolonged intravenous therapy. That this depends on the relation of the internal diameter of the vein to the musculature in its walls has been shown by histological studies.

Though this vein has undoubtedly been used for intravenous therapy before (as have all other superficial veins of the body), I can find no specific mention of it in the literature. The significance of the above finding has probably not been appreciated.

AdDENDUM.-Since this paper was written Mr. E. G. Dolton (1955) has used the method for massive blood transfusion. He states that the vein is absent in some cases and that this is indicated by the presence of minor superficial veins in the delto-pectoral groove. I have since found this to be true. I have had a recent case in which $500-750 \mathrm{ml}$. of $50 \%$ glucose was given daily through the cephalic vein for five days without any evidence of thrombosis. This is significant, as, lately, workers have advocated the insertion of a polythene catheter into the inferior vena cava to introduce this highly irritant fluid: venous thrombosis has sometimes followed.

I wish to thank Dr. W. Waldie for giving this method a trial at the Royal Victoria Infirmary, Glasgow, and for his cooperation in preparing this paper ; Mr. I. M. Orr and Mr. R. C. Shaw, of the Preston Royal Infirmary, and Mr. E. G. Dolton, of the Royal Hospital, Wolverhampton, for permitting me to give this method a trial on cases under their care; and $\mathrm{Mr}$. A. Robinson for the photograph.

\section{REFERENCES}

Doiton, E. G. (1955), Lancet, 1, 1052

Gordon, I., Grant, J. C., and Grigor, K. C. (1954). Ibid.. 2, 899.

\section{INFANTILE VISCERAL LEISHMANIASIS} IN THE MALTESE ISLANDS

BY

\section{T. J. AGIUS-FERRANTE, M.D., Ph.C., B.Sc. D.C.H., M.R.C.P.}

The main purpose of this paper is to record the docline in the incidence of leishmaniasis in the Maltese Islands over the past eight years, to comment on the literature perused during its preparation, and to review the insecticide residual technique used against the vector. It will also serve as an introduction to a later paper which will deal with epidemiological figures relating to. the part played by the sand-fly in transmission of the disease. The clinical picture is not given, as Debono's (1947) description of the illness is not to be improved upon.

\section{Historical Data}

Leishmaniasis must have been endemic in these islands for a long time. Its first mention in Maltese medical records was in 1909 ; however, the figures published by the medical and health authorities in the first 25 years of this century reveal an extraordinarily high incidence of deaths in children under 1 year from chlorosis, anaemia, splenomegaly, splenic anaemia, and leucosplenic anaemia. That most of these cases must in reality have been due to unidentified kala-azar is shown from the yearly increase in incidence of deaths in children from that disease and the corresponding decline when leishmaniasis became known to have an entity of its own.

The occurrence of splenic anaemia in young Maltese children was first identified with visceral leishmaniasis by A. Critien as early as 1909 ; a year later he discovered the disease in the dog-work that was later carried out by V. Mifsud and A. Bernard. However, it was not till 1931 that leishmaniasis began to be investigated thoroughly. Early in that year Dr. S. Adler asked the Government of Malta for facilities to continue the investigations on kala-azar which, with his colleague Theodor, he had been carrying out in Catania the year before. They were trying to establish whether the sandfly, which their research in Sicily indicated as the most important carrier of the disease, would be found to play here the same part in transmitting the disease. Two years later kala-azar was again mentioned in the principal medical officer's report, which dealt extensively with the first International Congress of Mediterranean Hygiene, held in Marseilles in the same year. It is therefore rather strange that leishmaniasis as a cause of death does not figure before the year 1938, when it was bracketed with " other disease due to protozoa."

In 1946, on my return from postgraduate training in the United Kingdom, leishmaniasis was, at my suggestion, made notifiable for the purpose not only of collecting full data on the epidemiology of the disease but also of starting a campaign against the vector by the insecticide residual technique. Mention should here be made of Dr. Francis Jaccarini, of Senglea, who was the first doctor in Malta to diagnose leishmaniasis in the adult.

\section{Incidence}

One peculiar characteristic of the clinical manifestation of the disease in comparison with other countries in the Mediterranean area is that we never encounter the cutaneous 
type-yet in Italy that type seems to occur quite often. (Table I). It is not a question of the cases being missed, as intensive research some 17 years ago for the express purpose of identifying the cutaneous lesion proved unfruitful.

Figures prior to 1947 are scanty and fragmentary, and do not in any way reflect the actual incidence of the disease ; figures for 1946 are not taken into account, as only those for the last trimester of the year are available.

The total number of cases in Malta during 1947-54, inclusive, was 777 (386 males, 391 females).

Age at Onset.-Two points are worthy of note : (1) leishmaniasis in the adult is rare and the visceral form affects children mainly; and (2) the commonest age group is from 2 to 3 years (Table II).

TABLE I

\begin{tabular}{|c|c|c|c|c|c|c|}
\hline & & & \multicolumn{2}{|c|}{1950} & \multicolumn{2}{|c|}{1951} \\
\hline & & & Visceral & Cutaneous & Visceral & Cutaneous \\
\hline $\begin{array}{l}\text { Italy } \\
\text { Malta }\end{array}$ & . & . & $\begin{array}{l}61 \\
66\end{array}$ & $\begin{array}{r}1,879 \\
0\end{array}$ & $\begin{array}{l}76 \\
58\end{array}$ & $\begin{array}{r}1,3 \leq 0 \\
0\end{array}$ \\
\hline
\end{tabular}

\begin{tabular}{|l|c|c|c|c|c|c|c}
\hline Age in years ... & -1 & -2 & -8 & -4 & -5 & -10 & $10+$ \\
No. of cases.. & 47 & 196 & 258 & 143 & 62 & 61 & 10 \\
\hline
\end{tabular}

TABLE III.-Monthly Incidence (Malta, 1947-54)

\begin{tabular}{|c|c|c|c|c|c|c|c|c|c|}
\hline & 1947 & 1948 & 1949 & 1950 & 1951 & 1952 & 1953 & 1954 & Total \\
\hline $\begin{array}{l}\text { Januarv } \\
\text { February } \\
\text { March } \\
\text { April } \\
\text { May }\end{array}$ & $\begin{array}{r}1 \\
8 \\
21 \\
19 \\
12 \\
22 \\
17 \\
15 \\
29 \\
27 \\
12 \\
8\end{array}$ & $\begin{array}{r}11 \\
24 \\
20 \\
16 \\
27 \\
27 \\
17 \\
20 \\
12 \\
18 \\
10 \\
2\end{array}$ & $\begin{array}{r}6 \\
9 \\
8 \\
12 \\
10 \\
7 \\
13 \\
9 \\
2 \\
6 \\
3 \\
6\end{array}$ & $\begin{array}{l}8 \\
1 \\
8 \\
6 \\
8 \\
4 \\
7 \\
4 \\
7 \\
4 \\
4 \\
2 \\
7\end{array}$ & $\begin{array}{l}0 \\
4 \\
3 \\
3 \\
5 \\
4 \\
8 \\
6 \\
8 \\
5 \\
7 \\
5\end{array}$ & $\begin{array}{r}3 \\
4 \\
3 \\
10 \\
5 \\
6 \\
2 \\
4 \\
7 \\
5 \\
3 \\
3\end{array}$ & $\begin{array}{l}5 \\
3 \\
7 \\
7 \\
5 \\
7 \\
5 \\
4 \\
5 \\
7 \\
4 \\
4\end{array}$ & $\begin{array}{l}4 \\
2 \\
4 \\
5 \\
2 \\
7 \\
5 \\
1 \\
7 \\
7 \\
1 \\
4\end{array}$ & $\begin{array}{l}38 \\
55 \\
74 \\
78 \\
74 \\
84 \\
74 \\
63 \\
77 \\
79 \\
42 \\
39\end{array}$ \\
\hline IVta1. & 191 & 204 & 91 & 66 & 58 & 55 & 63 & 49 & 777 \\
\hline
\end{tabular}

The yearly and the monthly incidences are shown in Table III. There was a striking drop in 1949, with a gradual reduction in the following years. This table may be somewhat misleading, as the day of notification of the illness does not correspond to the actual onset of the disease.

\section{Results}

The success of the treatment is reflected in the mortality rate (Table IV). Although the treatment is painful and complications and sequelae occur, leishmaniasis is not now regarded as such a serious problem. The figures in Table IV

TABLE IV.-Deaths

\begin{tabular}{c|c|c|c|c|c|c|c|c|c}
\hline & 1947 & 1948 & 1949 & 1950 & 1951 & 1952 & 1953 & 1954 & Total \\
\hline $\begin{array}{l}\text { No. of } \\
\text { deaths }\end{array}$ & 12 & 9 & 3 & 1 & 3 & 0 & 1 & 0 & 29 \\
\hline
\end{tabular}

compare well with those for 1923-32, when treatment was successful in only $59 \%$ of cases and the mortality rate for those who completed the whole course was $26 \%$. The sudden drop in the number of cases in 1949 and the falling incidence since then compel one to believe that these results are due mainly to the spraying of premises where cases were notified, using the D.D.T. residual technique. This opinion is shared by Dr. E. Stilon and Dr. P. Borg Mallia. Sanitation, of course, has not been neglected, and the eradication of breeding-places of the vector has been carried out in earnest. It is worth while mentioning here that the vector breeds also in the decayed stems of the prickly pear (Opuntia vulgaris), and is found, too, in the empty shells of molluscs, chiefly Helix, both of which are present in great abundance in Malta.

\section{Discussion}

Historically, the first attempt to reduce the number of sand-flies in Malta came from Captain J. P. Marett, R.A.M.C., in 1910 ; but his concern was to reduce sand-fly fever. On the other hand, the first attempt to eradicate leishmaniasis in these islands through an insecticide was made in 1912 by Dr. A. Critien, who, however, in advising parents to spray the floors with an insecticide, mistook his target, as his efforts were directed against Pulex irritans and Pulex serraticeps. When I first suggested the present treatment I was quite aware that Malone and Brooks (1944) had cast doubt on the part said to be played by the sand-fly as the vector. However, strong enough evidence has not been brought by the advocates of this view, and in the Mediterranean area the work of Adler and Theodor (1935) still holds good. Nor is this challenge new. In fact, the contention that the phlebotomus is not the only vector was raised in the Congress of Mediterranean Hygiene held in Marseilles in 1932, when several observers suggested that in mountainous areas not known to be sand-fly infested another insect vector should be looked for.

In these islands, the campaign, which was launched towards the end of 1946 , is entirely in the hands of the medical and health entomologist, Dr. P. Borg Mallia. Disinfestation with D.D.T. is carried out in all bedrooms, etc., as soon as a case of leishmaniasis is reported to him by the medical officers of health. After a month a second spray of D.D.T. is given. As our walls are made of coralline limestone, we did not feel the need for previously spraying them with phosphate solution to prevent the D.D.T. from forming chemical complexes with ferric ions and thus reducing its insecticidal power. Nor did we spray the animal reservoir. We are satisfied with the scheme, and are hopeful that leishmaniasis in Malta will soon be a very rare condition.

The only hazard of the scheme for human beings lies in the accidental swallowing of the insecticide by children-a thing which, to my knowledge, has happened only once.

Another type of danger, and to my mind the only serious one, is in the resistance that the vector may develop to the insecticide and in the acquisition of tolerance not only to the chemical at present used but also to allied ones. In fact, it is known that strains may become resistant to an insecticide ; for D.D.T.-resistant fly populations have developed already in the Middle East. A further disadvantage lies in the repellent action that the D.D.T. or its diluent may have on the vector, which may be stimulated to fly before contact is made with D.D.T. or a toxic dose has been acquired by it, thus, by putting the vector to flight, opening up new foci of infection. So far there is no evidence of either of these dangers, and one hopes that the disease will be eradicated before resistance develops.

\section{Summary}

Leishmaniasis is endemic in the Maltese islands. The cutaneous form is unknown; the visceral type affects children mainly between 1 and 3 years of age.

Since the end of 1946 disinfestation with D.D.T. has been carried out in all premises where leishmaniasis has been reported. The sudden drop in the number of cases in 1949 and the falling incidence since then appear to be due to the D.D.T. residual technique. The dangers that this scheme may entail are discussed. The treatment given has been successful, and the disease is now not such a serious problem.

My thanks are due to Dr. E. Stilon and Dr. P. Borg Mallia for advice given me in the compilation of this paper. 
BIBLIOGRAPHY

Adler, S., and Theodor, O. (1935). Proc. roy. Soc. B, 116, 494.

Basile, C. (1911). R.C. Accad. Lincel. Seduta del 19 Marzo, 1911.

British Medical Journal, 1952, 1, 543.

- 1953, 1, 1093.

Debono, J. E. (1947). Proc. roy. Soc. Med., 40, 155.

Hadaway, A. B., and Barlow, F. (1951). Bull. ent. Res., 41, 603.

Jacusiel, F. (1947). Ibid., 38, 479, 483.

Lancet, 1952, 2, 1170.

$-1953,2,441$.

Malone, R. H., and Brooks, A. G. (1944). Indian med. Gaz., 79, 484.

Marett, P. J. (1913). J. roy Army med. Cps, 20, 162.

Newstead, R., anu Binton, J. A. (1921-2). Ann. trop. Med. Parasit., 15. 103.

Rep. med. Hlth Dep. Malta, 1896-1954.

W.H.O. (1951). Tech. Rev Ser., No. 34

- (1953). Monog' Ser.. No. 16.

\section{FEEDING DIFFICULTIES IN INFANCY THEIR CAUSE AND PREVENTION}

BY

URSULA JAMES. M.B., M.R.C.P.

Medical Director, Violet Melchett Mothercraft Home and Nursery Training College

AND

\section{B. L. COLES, M.D., M.R.C.P., D.C.H.*}

In the considerable literature dealing with feeding problems in infancy that has been published in recent years, underfeeding and the mother's lack of education in infant management have been presented as the chief causes (Robbins, 1948 ; Illingworth, 1949 ; Dundon, 1951 ; Neale, 1952 ; Vining, 1952 ; Naish, 1953).

With this in mind, it seemed worthwhile analysing the admissions to the Violet Melchett Mothercraft Home, where the majority of infants are taken in on account of feeding difficulties, though a few are admitted because of general mismanagement or nutritional disorders following acute illness. The analysis deals with all babies, or mothers and babies, admitted during the year from October, 1953. Most of the cases were from the London County Council area, but some came from the Home Counties.

Our aim in the survey was to determine the factors which led to the feeding problems for which the children were admitted, and, by a careful study of the causes, to suggest how some of these problems might be avoided.

There were 173 admissions during the year, and the patients were divided into three main groups: (1) breastfed infants, (2) artificially fed infants, and (3) mixed feeders.

\section{Breast-fed Infants}

The 62 cases were subdivided into five groups (Table I).

Underfeeding.-Twenty babies were admitted on account of underfeeding at the breast. Many of the mothers had been feeding from 30 to 90 minutes at the breast in an

TABLE I.-Breast-fed Infants (62 Cases)

\begin{tabular}{|c|c|c|c|c|c|}
\hline $\begin{array}{l}\text { Underfeeding } \\
\text { Prematures } \\
\text { Normals for tuition }\end{array}$ & $\begin{array}{l}\cdots \\
\cdots\end{array}$ & $\begin{array}{l}20 \\
18 \\
12\end{array}$ & $\begin{array}{l}\text { Difficulties with breasts } \\
\text { Overfeeding } \quad . .\end{array}$ & $\begin{array}{l}\cdots \\
\cdots\end{array}$ & $\begin{array}{l}8 \\
4\end{array}$ \\
\hline
\end{tabular}

effort to satisfy the baby. Full breast-feeding was established in all five infants who had been sleepy and refusing to feed. Five babies were screaming most of the day and

*This work was done during the tenure of the A. M. Bird and Mabel Webb Research Scholarship, Royal Free Hospital School of Medicine. night, and full breast-feeding was established in one and breast-feeding with small complements in another. Mixed feeding was started in the remaining three, aged 10,12 , and 16 weeks respectively. Nine babies were having complementary feeds on admission. Five of these were sleepy, two were losing weight and two were restless. Full breastfeeding was established in five of these nine cases; the other four still needed small complements, but were doing well. One child was admitted because of vomiting and screaming. His mother had had a lavish amount of milk at one time, but her worry over the vomiting probably caused a decrease in lactation and the baby was underfeeding. On discharge he was fully breast-fed.

Premature Infants.-Eighteen of these babies were admitted in order to keep the mother and baby together and to establish breast-feeding. Most of them came from hospitals and were admitted initially without their mothers until we felt that their vigour was good enough to allow breast-feeding. Several infants had already started on bottle or breast, but these were often exhausted and required tube or Belcroy feeding until they could tolerate bottle-feeding easily. Breast-feeding was then started by allowing the baby to suck for a few minutes at one feed. The sucking time and the number of feeds at the breast were increased according to the child's energy. The most difficult babies were those who had been forced with early feeding and came to us already tired. Time was always saved in establishing breast-feeding where the baby had never been allowed to get tired and sleepy. The inevitable setbacks due to exhaustion led to disappointment and depression in the mother, often accompanied by decrease in lactation. During the time that the mother is expressing her milk for the baby it is important to inspect the breasts daily to ensure that expression is complete and that no congestion, with consequent mastitis and abscess formation, is pending. The nipples should receive any necessary attention during this period so that any defects are rectified before the baby starts sucking. On discharge, 13 of the babies were entirely breast-fed, and the other five (including twins) were breastfed with a fixed complement after certain feeds.

For Tuition.-Twelve normal infants were admitted with their mothers, who had previously arranged admission for tuition. Full breast-feeding was established in all cases after a stay of from one to two weeks.

Difficulty With Breasts.-Eight babies were admitted with difficulties on account of abnormalities of the mothers' nipples. All the mothers said that their breasts had been examined on the first visit to the antenatal clinic but not again. Hand expression of the breasts had not been taught, nor had the mothers been instructed about lactation ; most had been given little assistance in getting the babies on the breast in the early days. Two mothers, one with cracked nipples and the other with inverted nipples, had been giving expressed breast milk at home. Two had engorged oedematous breasts on admission, and developed abscesses within 24 hours. Three other mothers were giving feeds from the breast despite the great pain caused by cracked nipples. In two of these cases the nipples were also retracted. Plastic shields were used for those mothers who had retracted or inverted nipples. Those with cracked nipples gave up feeding for several days until healing was complete. Seven mothers achieved full breast-feeding, but one baby needed small complements after two feeds each day. Careful and repeated examination of the breasts during pregnancy is important. Waller (1950) found that one-third of all mothers had defects in one or both nipples when tested in early pregnancy, and that correction could be obtained in almost all by the use of shields.

Overfeeding.-Four babies, aged 16-28 days, were admitted on account of vomiting after feeds, screaming and restlessness between feeds, and in one case choking during feeds. Two had normal stools and two were passing undigested green stools with little consistency. One had sore buttocks. Test feeding revealed that all were taking overlarge feeds; two were also feeding very quickly, and one 